\title{
Porcelain gallbladder
}

\section{Sajid Ansari}

Published online: 28 August 2013

(C) Indian Society of Gastroenterology 2013

Porcelain gallbladder is considered a rare condition characterized by calcification of the gallbladder wall and is found in $0.06 \%$ to $0.08 \%$ of autopsies [1]. This computed tomographic (CT) scan image (Fig. 1), from a 59-year-old woman, demonstrates this

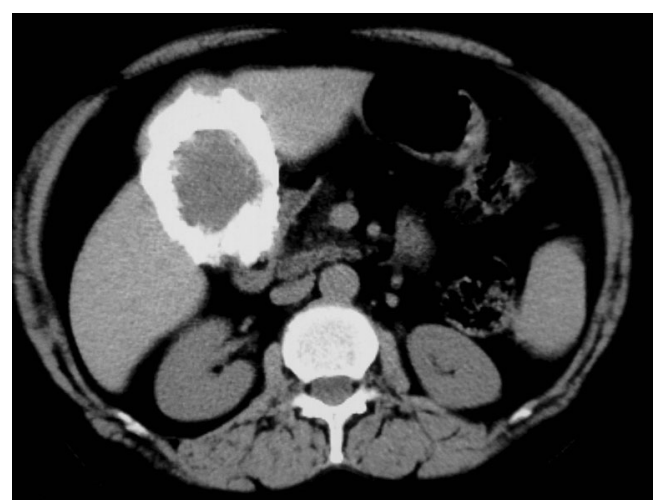

Fig. 1 CT abdominal scan showing circumferential calcification in the gallbladder wall abnormality. She presented with 2 months history of pain in the right upper quadrant and intermittent intolerance to fatty foods and was found to have a hard palpable mass in the right upper quadrant of the abdomen. Plain film of the abdomen revealed an oval calcification in the right upper quadrant, and ultrasound examination showed circumferential calcification of the wall of gallbladder. Most patients are asymptomatic. It is associated with an increased risk of gallbladder malignancy, ie. between $5 \%$ and $12 \%$ [2]. The most common type of malignancy is adenocarcinoma which accounts for $80 \%$ of porcelain gallbladderassociated cancers. Cholecystectomy should be considered.

\section{References}

1. Polk HC Jr. Carcinoma and the calcified gall bladder. Gastroenterology. 1966;50:582-5.

2. Kim JH, Kim WH, Yoo BM, Kim JH, Kim MW. Should we perform surgical management in all patients with suspected porcelain gallbladder? Hepatogastroenterology. 2009;56:943-5.
S. Ansari $(\bowtie)$

Department of Radiodiagnosis and Imaging, B P Koirala Institute of

Health Sciences, Dharan, Nepal

e-mail: drsajidansari2012@gmail.com 